\title{
THE IMPACT OF SOCIAL WELFARE POLICIES ON SOCIAL DEVELOPMENT IN SOUTH AFRICA: AN NGO PERSPECTIVE ${ }^{1}$
}

\section{A Lombard}

\section{INTRODUCTION}

The democratic government of South Africa has adopted a developmental framework and is aspiring towards being a developmental state (Department of Social Development, 2006a:2). However, the aspiration to become a developmental state is being seriously questioned in view of the increasing gap between the rich and the poor over the country's thirteen years of democracy. Although it was expected that it would take a considerable time to eradicate the legacy of the past (RSA, 2006:5) it is a matter of great concern that the levels of poverty and inequality are on the increase in South Africa. Although South Africa's neo-liberal macro-economic policy contributed to an economic growth rate of 4,9\% in 2006 (RSA, 2007a:5), the policy is criticised for not sufficiently achieving economic development. The social welfare sector is one area in which the macro-economic policy impacts on government's responsibility for, and accountability to, the vulnerable and the marginalised in society.

In line with its developmental agenda South Africa adopted the White Paper for Social Welfare (RSA, 1997) which adopts a developmental approach to social welfare with the intention to address issues of poverty and inequity, and promote social development by integrating social interventions with economic development (Department of Social Development, 2006a:2). Although the said White Paper provided the policy framework for welfare to incorporate a development focus, the implementation of this policy is a huge challenge, given the transformation agenda of a new democracy.

To bridge the gap between the rich and the poor, the elected democratic government invested more money in social security at the expense of social welfare service delivery and the achievement of social development goals. Hence, despite having adopted a developmental approach to service delivery, the social welfare sector's progress in delivering on its developmental mandate is lagging behind. As far as the history of social welfare in South Africa is concerned, social security had made up the lion's share of the social welfare budget. Currently the number of beneficiaries of social assistance is 12 million persons (RSA, 2007b:4), i.e. almost a quarter of the South African population. For the year 2003/2004 this was 2,9\% of the Gross Domestic Product (GDP) (RSA, 2007b:4). Earlier warnings by the Minister of Finance, Trevor Manual, that a better balance ought to be found between growth in welfare spending and social development (RSA, 2005) were overshadowed by the immediate impact of social security to alleviate poverty as the government's priority anti-poverty programme. Although social grants make a huge contribution to alleviate the dire poverty of many households in South Africa, the financial burden of social security is increasing and it has been noted as becoming unsustainable (Department of Social Development, 2006a:5). The government now acknowledges that no exit levels were planned for social grants (Department of Social Development, 2006b). This reality emphasises that, whilst caring for the vulnerable and the marginalised and thus achieving social justice, the government has not fully delivered on its social development goals. The Deputy

\footnotetext{
${ }^{1}$ I acknowledge Dr Laetitia Botha, Director: Gauteng North Services to People with Disabilities for her expert view from an NGO perspective.
} 
Minister of Social Development, Jean Benjamin, expressed this neglect as follows: "the intensive social security focus has been to the detriment of other developmental social services" (Department of Social Development, 2005a:1). One of the mechanisms for the social welfare sector to achieve social development is thus through developmental social service delivery.

In curbing the negative impact of the social welfare budget on social services, a positive step forward was the historical event of shifting social assistance to an independent agency with its own budget, i.e. the South African Social Security Agency (SASSA), from April 2005. Although this was a victory for the social welfare services agenda and budget, it compounded the crises in social welfare service delivery because it exposed the neglect of social welfare service delivery and the failure to realise the aim of achieving social development goals through services over the past thirteen years.

This neglect has led to, among other things, deepening poverty, poorly developed protection services and an increase in social pathologies (Department of Social Development, 2006a:5). Whilst the demand for social service delivery was increasing, the skills flight of social workers, low salaries, the discrepancy in salaries between social workers in government and those at NGOs, their poor working conditions and a lack of resources for service delivery in the NGO sector brought social service delivery to the brink of collapse in 2005 . The relationship between government and NGOs deteriorated to the level of a total breakdown of trust, which resulted in protest marches in the Gauteng Province in May 2005.

In 2006 government openly declared that it had neglected NGOs and social service delivery (Department of Social Development, 2005a). This acknowledgement laid the foundation for a new start in the social welfare sector and created a platform for strengthening the partnership between the government and NGOs. The Department and hence government were now challenged to develop and deliver a social development strategy across the social sector, including participation of government departments, publicly-funded non-government organisations and civil society at large (Gauteng Welfare Summit, 2006:7). The social welfare sector had to reposition itself (Department of Social Development, 2006a:6) in terms of statutory and developmental social services by leading and facilitating the integration of prevention, intervention and rehabilitation strategies (Gauteng Welfare Summit, 2006:4). The social welfare sector was now held accountable for its policy framework to impact on social development and, in the absence of resources to achieve this, was confronted with serious challenges to deliver on its social development goals. Although progress has been made (Green \& Nieman, 2003; Lombard, 2005; Patel, 2005), social welfare as a sector has not yet delivered on its social development agenda as was intended with the adoption of the White Paper for Social Welfare (RSA, 1997).

Whilst the lack of resource capacity was a major reason for not delivering on social services, the lack of proper guidelines as to how social welfare should achieve social development goals was an even bigger obstacle. Besides the broad social welfare policy framework of the White Paper for Social Welfare (1997) and the Financial Policy for Developmental Social Welfare Services (1999), there were no specific guidelines as to how integrated developmental social services and social development would be achieved. The public acknowledgement of the neglect of social services in 2006, on the one hand, highlighted the crisis of the sector but, on the other hand, it also paved the way for the birth of the Integrated Service Delivery Model (ISDM) towards improved service delivery. In this paper this policy will be analysed in terms of its impact on social development goals from an NGO perspective with specific reference to NGO responses from the Gauteng Province. 


\section{THE INTEGRATED SERVICE DELIVERY MODEL (ISDM)}

With the ISDM the Department of Social Development seeks to provide a comprehensive service that will reduce the burden on social security (Department of Social Development, 2005a:1). According to the Deputy Minister for Social Development, social security should therefore be a measure that largely provides immediate relief, with the possibility of beneficiaries exiting from the system and being redirected to developmental social welfare services to ensure sustainability of intervention efforts (Department of Social Development, 2005a).

The ISDM, with its values and principles embedded in the Batho Pele principle of "people first", aims to "provide a national framework that clearly determines the nature, scope, extent and level of work that constitutes the service delivery model for developmental social services ... and provide a basis for determining appropriate norms and standards for service delivery, which will in turn provide a basis for funding and greater efficiency and effectiveness in service delivery" (Department of Social Development, 2006a:7). The ISDM is one of a series of inter-related documents that give effect to the implementation of the White Paper for Social Welfare (1997), including the Policy on Financial Awards to Service Providers (Department of Social Development, 2005b), and the Procedure Guidelines for the Implementation of the Policy on Financial Awards to Service Providers (Department of Social Development, 2005c) and it must therefore be read in conjunction with these (Department of Social Development, 2006a:4). This paper will, however, indicate that these financial policies do have significant implementation limitations for developmental social welfare services to deliver on social development goals.

Although it is too early to evaluate the impact of the policy on the outcomes of social development from a beneficiary perspective, it is possible to analyse the impact of the policy on how it positions and re-orientates the social welfare sector, and in particular NGOs, for implementing developmental social services, in partnership with government, to achieve social development goals. In October 2006 the social welfare sector in Gauteng, the most densely populated of the nine provinces in South Africa, conducted a social welfare summit to review the ISDM for its implementation potential in achieving integrated developmental social services. During this summit a review was prepared by the Gauteng Department of Social Development and the NGO sector. The strengths and the challenges of the ISDM based on the practice experiences of the NGO sector, in particular, were highlighted. This paper will report on the outcomes of these reviews and will further analyse and add to the debate on the challenges ahead for South Africa in promoting social development through social service delivery. The Gauteng Welfare Summit (2006) marks a new beginning for government and NGOs in the province to start rebuilding their relationship by finding common ground on the strengths and the challenges of the ISDM and in determining the landscape for the way forward.

\section{Strengths of the ISDM}

Derived from the Gauteng Welfare Summit (2006:11), the strengths of the ISDM, as agreed upon by both government and NGOs, represent a major advance in policy which takes the social welfare sector forward in crucial ways, namely:

- It describes the core business of the sector;

- Clarifies the constitutional, legal (focused areas) and policy mandate of the sector;

- Provides a framework within which all role players can locate themselves and strengthen the linkages between them;

- Highlights the human resource challenges facing the sector; 
- Begins a process of putting basic norms and standards for social service delivery in place;

- Begins to equip the sector to do what it has to date never been able to do, i.e. to make a proper case for the allocation of the resources it needs to carry out its responsibilities.

Although these strengths reflect a positive way forward in many areas, such as norms and standards for social service delivery, the work has only begun. The Department of Social Development is facilitating the process of developing service delivery norms and standards in conjunction with other stakeholders (Gauteng Welfare Summit, 2006:8).

Embedded in the strengths of the ISDM are also certain limitations and therefore challenges in implementing the model. When the model was adopted in 2006, however, it was never claimed that it was a comprehensive or fixed model. From the onset the Department has emphasised that the model "is not cast in stone but will grow and develop as the sector moves forward" (Gauteng Welfare Summit, 2006:12). This paper is an attempt to make a contribution to this effect.

\section{Challenges of the ISDM}

There is an agreement amongst government and NGOs that critical areas for effective social service delivery include: determining standards and norms for practice to provide a basis on which services can be costed; building resource capacity; designing and maintaining a comprehensive data base for social service delivery; having a human resource plan for the sector and strengthening the partnerships between government and NGOs (Gauteng Welfare Summit, 2006). Underpinning these implementation challenges are the conceptualisation and contextualisation issues which form the basis for successful implementation of the ISDM. Amongst these are the relationship and context of welfare and development; the scope of integrated social services within a developmental paradigm; social services and community development; partnerships; funding principles and models; and indicators for developmental social service delivery which constitute major challenges for implementing the ISDM.

At the time of the emerging development paradigm for social welfare Lombard (1996:162) wrote: "Misconceptions and misunderstanding create many uncertainties and even resistance and fear among social welfare workers". This trend continued throughout the following decade up to today as captured in the ISDM: "Over the last decade, the notion of what constitutes developmental social welfare service delivery has been a matter of debate, misunderstanding and misinterpretation" (Department of Department of Social Development, 2006a:3; De Jager, 2005). Why this is the case would certainly make for an interesting debate, but if the attempts over the years to guide the process of how to implement the developmental approach are analysed, it now appears that perhaps the how took so long to realise, because the what was perhaps never as fully understood as was assumed. Embedded in this assumption is (1) the view that professionals, especially at grassroots level, are reluctant to read and participate in policy processes (Gray, 2006), resulting in their being ignorant and uninformed on policy documents and directives such as the ISDM; and (2) that there is a lack of common understanding of concepts and contexts, which implies not knowing what needs to be achieved. Without knowing the what, the how will be difficult, if not impossible, to achieve. A lack of clarity on the what represents conceptualisation issues which, in turn, impacts on funding. The NGO sector emphasises that to be able to fund social services, it is necessary to first define what services constitute social welfare services (Social Development Summit, 2006:15). In this paper, selected what and how issues will be addressed. The "what" constitutes the relatedness of welfare and development; integrated generalist and specialist social services; and the positioning of social services and 
community development. The "how" encompasses developing an adequate human resource base; partnerships; funding; indicators for monitoring and evaluation of social services; and a legislative framework for the social welfare sector.

\section{Relatedness of welfare and development}

Until such time that the relationship between "welfare" and "development" is clarified, the South African welfare sector will struggle to come to grips with, and deliver on, its social development agenda. Because of the historical connection of social welfare with apartheid (Lombard \& Kleijn, 2006:215; Sturgeon, 1998:26), there is a notion that "social welfare" must be replaced with "social development". The renaming of the national and some provincial departments of social welfare as departments of social development is testimony to this belief. However, this is contradictory to its own mandate. In the ISDM reference is made to "social development", "developmental social welfare" and "developmental social welfare services", implying a clear identification with government's "social welfare mandate" (Department of Social Development, 2006a:12). In order to deliver on its social development goals, the social welfare sector should thus clarify its mandate with regard to developmental social services and social development as far as their relatedness and distinctions are concerned.

Social development is considered to be multidisciplinary and cuts across sectors such as health, education, economic development, social security and welfare services (Patel, 2005:206). Social work is one of the professions involved in the delivery of developmental social welfare (Patel, 2005:206). Midgley's (1995:8) internationally recognised definition of social development as "a process of promoting people's welfare in conjunction with a dynamic process of economic development" indicates the link of social development to social welfare.

Social development needs to be clearly distinguished as (1) an ultimate (end) goal of development activities; and (2) as an appropriate approach to social welfare (Midgley, 1995:13) and thus an intervention strategy that incorporates social and economic processes to achieve social development as its ultimate goal. Social development cuts across many government departments' responsibilities (Social Development Summit, 2006:15) and can hence not be claimed solely by one department, even if that department happens to be the coordinating department for social development (Department of Social Development, 2006a:13).

The ISDM classifies developmental social service delivery in two ways: by means of (1) levels of intervention, which refers to prevention, early intervention, statutory intervention/residential/ alternative care and reconstruction and aftercare; and (2) in terms of classification by means of the nature of core services, i.e. promotion and prevention services, rehabilitative services, protection services, continuing services, and mental health and addiction services (Department of Department of Social Development, 2006a:18-21). In both these classifications "traditional" social services are clearly reflected. The outcry for clarifying the confusion between "traditional welfare" and developmentally focused social services is clearly heard in the following plea of the NGO sector (Gauteng Welfare Summit, 2006:11):

If we accept the model [ISDM], we need to stop talking about "moving away from traditional welfare responses". Much of what our sector has to do falls squarely in the domain of such responses - e.g. protection for abused and abandoned children, finding families for orphans, treatment of addictions, rehabilitation of offenders, care of the frail elderly and so forth.

Clearly the protection, rehabilitation and care that the NGO response refers to are in line with the above core service categories of the ISDM. The notion that "welfare" needs to be replaced with 
or shifted to "social development" is contradictory within the ISDM document itself where it states: "The goal of social development is the promotion of social welfare" (Department of Social Development, 2006a:13). The ISDM refers to Midgley's (1995:14) definition of "welfare" in the broadest meaning to connote a condition of social wellbeing which occurs when social problems are satisfactorily managed, social needs are met and social opportunities are created (Department of Social Development, 2006a:13).

The question is why there is this belief that a developmental approach to social welfare implies a shift from "welfare" to "development", and that the replacement of social welfare with social development must be achieved by South Africa's social welfare sector? Lombard and Kleijn (2006:215) debate at length that the association of casework and statutory work with apartheid does not mean that casework and statutory work interventions should not be used in social service delivery within a development paradigm. It was not the intervention methods per se that were ineffective and discriminatory which excluded and deprived many South Africans from access to services, but the social welfare residual model and thus the policy framework that informed its implementation (Lombard \& Kleijn, 2006:215). Furthermore, the fact that "[d]evelopmental social welfare then is the name given to South Africa's new welfare system" and that it is "... moulded by the theory of social development as embodied in the White Paper for Social Welfare ...") (Gray, 2006:S53), does not mean that it equals social development. What then is the focus of the "shift" in relation to what was "traditional" if social service delivery is to be shaped to achieve social development (end) goals?

It is exactly the perception amongst social workers that "shift" means a total "abandoning of the past" that creates the uncertainty, confusion and resistance surrounding the transition to a "developmental" focus for social service delivery. The implementation of "traditional" social welfare responses, including rehabilitation, protection and casework, should "shift" from an individualist, residual social welfare policy embedded in a medical model, to social justice, empowerment, capacity-building, strengths-based, people-centred and sustainable approaches which are founded in a developmental social welfare policy that will facilitate and promote human, social and economic development (Department of Social Development, 2006a:13). "Developmental" means that whether the intervention is rehabilitative, preventative or protective, the vulnerable and marginalised are approached in a manner that focuses on "social protection, the maximization of human potential and on fostering self-reliance and participation in decisionmaking" (Department of Social Development, 1996a:12). In this process, clients and communities' assets and strengths are the point of departure and they are involved in the intervention as partners in decision making on issues affecting their lives and destiny.

The ISDM indicates that there is a need for a development approach "that is based on the strengths of individuals, groups or communities and promotes their capacity for growth and development" (Department of Social Development, 2006a:13). Poverty and vulnerability have both social and economic dimensions (Schoeman, 2001). Poor people are socially excluded because they are, amongst other things, marginalised from mainstream economic activities. One of these "new approaches" to promoting development social welfare is social development (Midgley, 1995:2). Hence, if social welfare wants to contribute to promoting social development, professionals such as social workers must "shift" their intervention approaches to include social development and not "replace" all approaches with social development.

There is thus a huge difference in shifting approaches as opposed to "moving away from the traditional welfare responses" (Department of Social Development, 2006a:11). The shifting of 
approaches does therefore not mean shifting from "welfare to development", but implies incorporating development in "welfare", thereby achieving a shift from "welfare" to "developmental welfare". The NGOs' plea that "[t]he model [ISDM] should also help put to rest the notion of "shifting from welfare to development"" (Gauteng Welfare Summit, 2006:11) is therefore strongly supported.

Just as much as a developmental approach to social welfare does not equal community development (Lombard, 1996:162), social development does not equal developmental social welfare. The interchangeable use of the social development approach to social welfare and developmental social welfare as if they hold the same meaning should therefore be rejected. A developmental approach to social welfare has a much wider implementation scope in that it challenges social service professionals such as social workers to deliver social services from a "developmental" perspective incorporating approaches as indicated above. Gray (2006:S53) concurs: "welfare is defined more broadly as social development within the developmental paradigm".

Midgley (1995:25) affirms that the social development approach does not "negate the other approaches, or minimize their efforts to enhance people's well-being ... but within the context of economic development, seeks to link the social service to economic development in a dynamic way". It is thus the social development approach that provides the social welfare sector with the key to make a meaningful contribution to the alleviation of poverty and inequities in society and to establish professionals such as social workers, as important social partners in achieving social development (end) goals. The social welfare sector has not been able to use social development as key, because it is not clearly distinguished and utilised as an approach. Gray (2006:S54) contextualises the essence of this debate and the reasons for the slow delivery of social welfare in achieving social development goals aptly:

If anything, social development, as a theoretical approach [my emphasis] anyway, has been adopted whole-heartedly without thought as to how this was supposed to work in practice. It has thus been very effective in reshaping welfare policy in South Africa. However, as to whether or not it has been effective in alleviating poverty and social problems, this is a very different matter... the government has veered away from social development, leaving the developmental welfare system floundering in uncertain and turbulent waters ...

In conclusion, Patel (2005:322) states: "The case for developmental social welfare needs to be made by the sector itself". It is the premise of this paper that, if the social welfare sector wants to be a significant partner in achieving social development goals in South Africa, we need to clearly distinguish between a "developmental approach" to social welfare service delivery in facilitating and promoting human development, and social development as (1) an integrated end goal and (2) as an approach and strategy to facilitate and achieve integrated human, social and economic development.

\section{Integrated generalist and specialist social services}

During the Gauteng Welfare Summit (2006:14) the NGOs indicated that "a problem faced by the sector is that there has never yet been a proper engagement with the nature of the balance between specialist and generic services, or that between rehabilitative, protective, preventive and developmental services, or with the issue of how a network of accessible one-stop services can be rolled out". The White Paper for Social Welfare (1997:20) indicates that a "balance will be struck between rehabilitative, protective, preventive and developmental interventions" which, according to Patel (2005:193), should happen through the delivery of generalist services and practice. 
Patel (2005:192) indicates that the new social welfare policy envisaged a shift from specialist to generic services, which she also referred to as "generalist services". According to Patel, generalist welfare services were to be encouraged as these would be more holistic and could increase access to services in disadvantaged communities (2005:192).

In 2001 Loffell (in Patel, 2005:193) called on the welfare sector to develop policy options to find a balance between generalist and specialist services. The Department of Social Development, however, is currently taking a strong position in advancing specialised fields in social work as a strategy to build career paths for social workers. This debate, however, cannot be separated from the premise of the ISDM of an integrated approach to social service delivery. What is thus required in the generalist versus specialist debate is an indication of how it fits within an "integrated social service delivery" perspective. In its review of the ISDM, the NGO sector highlighted that the ISDM uses an approach that is an advance on previous efforts in that it is designed to maximise the integration of services (Gauteng Welfare Summit, 2006:16). However, NGOs identified gaps in the ISDM's identified target groups of children, youth, families, women and older people, and asked where do single adult males, offenders or addicts fit? (Gauteng Welfare Summit, 2006:16). In addition, the classification of core services combines levels of services (promotion and prevention, rehabilitation, protection ongoing care) and includes in this category the specialist fields of mental health and addictions (Gauteng Welfare Summit, 2006:16). This clearly creates confusion.

To strike the required balance, the point of departure for categorisation has to do with who requires what kind of services on what levels. Poor and vulnerable children and youths, for example, do not only need care. They need to be capacitated to become adequately skilled and self-reliant to be able to access opportunities from the economic sector (Gauteng Provincial Government, 2005:6). Skills development is required to capitalise on opportunities created by economic development (Gauteng Provincial Government, 2005:7).

Within an integrated development approach, the debate should not be on "generalist" versus "specialist" services per se. It is rather when the specialist focus shifts from the poor and the marginalised to the middle and upper classes in society that the "generalist" versus "specialist" debate attaches a different meaning and interpretation of the social welfare sector's role in achieving social development goals. The social welfare sector should seriously intervene in social work practice and training when specialised services shift so far away from the poor and the vulnerable that it becomes an elitist category of social services. Social work educators play a vital role in preparing students for a balance in generalist and specialised services to the poor and the vulnerable, since it has already been observed that many social work students indicate that they do not wish to work within poverty-stricken contexts when they enter practice.

Although there is nothing wrong with highly specialised services, it must never be at the cost of the poor and the vulnerable. The ISDM must therefore clearly contextualise generalist and specialised social services within an integrated developmental social service delivery framework which aims primarily to target the poor and marginalised.

\section{Positioning social services and community development}

One of the major limitations of the ISDM is the artificial separation of social services and community development. It is similar to separating the individual from his/her environment. The ISDM indicates that the National Department of Social Development renders services through three broad programmes of Social Security, Social Welfare Services and Community Development (Department of Social Development, 2006a:16). Elsewhere in the ISDM social 
services and community development are positioned differently in a "developmental" framework of social service delivery: "Whilst recognising the role of social security, services are defined in terms of two broad categories that constitute developmental social services, namely developmental social welfare services and community development" (Department of Social Development, 2006a:5). This distinction of the broad service programmes is critical for practice. Too many social workers spend their time, in some instances two days per week, in processing applications for social grants at the expense of engaging in social services activities that could promote and achieve social development. Although it will always remain the responsibility of social workers to ensure that those who qualify for social grants are linked with the social security system, they do not have to process the applications themselves. Social auxiliary workers, who are now being targeted by government to be recruited, trained and deployed throughout the provinces in South Africa to relieve the burden of social workers, are ideally positioned to take up this role. The ISDM must be very explicit in demarcating responsibilities for the human resource base of social welfare services if it wants to deliver on its mandate to achieve social development goals. Likewise, the role of community workers in social service delivery must be clarified in the ISDM.

In their review the NGOs emphasised that there is a lack of clarity as to how broad-based community development which puts people and communities at the heart of development fits into the ISDM (Gauteng Welfare Summit, 2006:13). Although community development programmes can be an independent entity, community development as a strategy for social development (Midgley, 1995:115) is inherent in developmental social service delivery which is aimed at achieving social development goals. The ISDM indicates that " $[\mathrm{t}]$ he development approach is therefore able to promote the meeting of emergency needs of vulnerable households, individuals and communities while ... developing appropriate strategies for sustainable socio-economic development" (Department of Social Development, 2006a:16). Community development and more specifically community economic development is therefore a possible strategy to utilise in the appropriate social service context.

The ISDM's separation of "welfare" and "development" is confusing given the multi-pronged approach of the model "aimed at addressing the social welfare and development needs of target groups in a holistic and integrated manner" (Department of Social Development, 2006a:16). What, for example, is the "welfare" need and what is the "developmental" need when the target population of unemployed mothers with young children is the focus of integrated social service delivery? The reality of unemployed women is poverty, which means the real "need" is productive income and this, addressed from an integrated developmental perspective, could include immediate poverty relief such as food security and/or applying for a child-care grant as interim measures, whilst simultaneously engaging or linking the women with a skills development community programme or network which could build their capacity for income generation. The question again is which part of the intervention is "welfare" and which is "development", given the integrated nature of the intervention approaches to address the "need"? Developmental social services should not separate needs into a "welfare" or "developmental" context if they are approached in a holistic, integrated manner. This confirms that developmental social services are not about shifting from "welfare to development" but about integrating development into service delivery, thus shifting from a residual to a development approach. This stance does not imply that community development cannot be a separate programme, as will be discussed next. The argument is that "integrated developmental social services" can never exclude community development approaches and strategies. 


\section{Developing an adequate human resource base}

The impact of the artificial division of social welfare and community development is reflected in the human resource capacity responsible for implementing and achieving community development. The ISDM refers to the many categories and levels of personnel and the volunteers who together must deliver the services for which the sector is responsible, and the vital importance of training for all concerned (Gauteng Welfare Summit, 2006:16). The White Paper for Social Welfare (1997:32) paved the way for the appointment of other categories of social service personnel, especially because of an "over-reliance on professional social workers". Whilst this is a positive step forward in building human resource capacity in the social welfare sector, it has not yet taken the sector forward in terms of achieving its social development agenda. The major reason is that the search for "a new cadre of community of social development officers/workers" to focus on community development was not based on a proper analysis of what these workers were suppose to do to "shift to a social development approach" (Department of Social Development, 2006a:15) in relation to the role of those professionals already available at grassroots level in communities, such as social workers. No analysis was done of available research or a situation analysis undertaken to determine the impact that social workers are either already making in communities or the potential impact that they could make if clear guidelines were in place to facilitate a shift of social service delivery towards a developmental approach where community development intervention strategies are utilised to achieve social development. While the ISDM can play a facilitating role in providing such guidelines, it rather contributes to the confusion because of the explicit division of social services and community development as two separate programmes. The Department of Social Development's challenge to take a stance towards integration is unfortunately difficult, because it was driven by a political decision to appoint community development workers without first demarcating their role and responsibilities in relation to other social service professionals, such as social workers.

The open agenda for finding "a new cadre of community of social development officers/workers" is reflected in the unspecified focus of appointees in this "cadre". Practice is now faced with the employment of "community development workers" with "qualifications" ranging from a few months in-service training to professional degrees in the specialised field of community development. This creates huge discrepancies in claims of "professional status" and a consequent conflict in salary scales across disciplines and between professionals and lay community workers. This concern is affirmed in the focus of the Social Development Strategy for the Gauteng Province (Gauteng Provincial Government, 2005:22), which incorporated in the strategy the activity to mobilise residents of communities to participate in social development programmes as "Community Development Workers". In this strategy, in our view, the role of "community development workers" is outlined below as merely that of community liaison officers:

Community mobilization includes the role of "Community Development Workers" who are based at local/community level to take government and services directly to the people. Government through interactions with communities realised that there were people who still did not get access to or did not know how to access, services they were entitled to. "Community development workers" are positioned to help make the machinery of the bureaucracy work more efficiently, increasing the effectiveness of systems of all levels of government and strengthening government's awareness of and capacity to respond to the needs of the people at the local level (Gauteng Provincial Government, 2005:21-22).

When guided by the vision that "[t]his emerging corps of social development workers should help to fill in some essential gaps in our service system, including those mentioned earlier to 
community development, assuming that their training is designed accordingly" (Gauteng Welfare Summit, 2006:16), there is no doubt that there should be a clear analysis of what these "gaps" are and what kind of worker should fill what specific gap. The Gauteng Provincial Government, for example, has identified the SMME sector as one of the critical mechanisms in addressing direct poverty reduction and creating job opportunities. The strategy specifically indicates that this can be achieved through focused efforts to ensure the meaningful participation of women, people with disabilities, youths and other marginalised sectors in society (Gauteng Provincial Government, 2005:19).

At the Gauteng Welfare Summit (2006:13) the NGO sector requested that the roles of professionals, community members and government appointees in linking communities to access social services should be clearly distinguished. Because community development can be defined as a philosophy, programme, process or intervention method (Lombard, 1991:115), and is an intersectoral approach (Ife, 1995), the boundaries of community development can never be cast in stone, but can either be attached to one specific discipline or be a stand-alone programme in itself. Thus, an attempt to distinguish the "roles" of various role players for purposes of implementing the ISDM, should rather be guided by principles for role categories such as "community liaison", "community facilitation" and "community development" as opposed to exact role definitions. Such a clarification will demarcate core boundaries for claiming the title of such a category, while allowing other social service professionals to use strategies that might include community liaison or community development in achieving specific intervention goals. It will furthermore facilitate holistic, integrated community development, which will take social development forward in South Africa. Most importantly, it will finally end the everlasting debate on whether social workers have a role to play in community development.

\section{Partnerships for social development}

For effective policy implementation, there is a need for ongoing co-operative policy making, planning and budgeting between all role players in the sector, which includes a need for clearly defining the boundaries of the responsibilities of the sector (Gauteng Welfare Summit, 2006:12). Lombard and Du Preez (2004) and Gray and Crofts (2004) respectively outlined the challenges for building partnership in social development and marrying the strengths and resources of diverse interest groups. These publications indicate the context for what is required to establish a well-founded partnership between various role players in a partnership for social development.

For the purposes of this paper, the focus will be on how the policy directives of the ISDM (Department of Social Development, 2006b) and the Policy on Financial Awards to Service Providers (2005b) impact on the partnership between NGOs and government, in particular, in achieving social development goals. Finances underpin policy implementation and, although there are many more components to a partnership between government and NGOs (Lombard \& Du Preez, 2004), funding has always been a very contentious issue which continuously influences and challenges the stability of the partnership. It was in the area of finances that the breakdown occurred between government and NGOs which was alluded to earlier on. In the financial year (2005-2006) the Department of Social Development decided to reduce the financial allocations to NGOs in Gauteng by 25\%, which came in the wake of no increases for NGOs for several years (Social Development Summit, 2006:12). Although the decreases did not take place because of the severe and unanimous protest of NGOs, the initial decision impacted on the trust and the perceived commitment of government to honour its partnership with NGOs, who often provide services that are primarily the government's responsibility. The provision of funds to NGOs is the difference between social welfare service delivery or not. Lack of funds forces cut backs to the 
scope of services; it impacts on the quality of services; it creates even more inadequate salaries for social work and other staff, resulting in high staff turn-over as well as general conservative/limited consideration of instituting services for observed new needs. The most severe impact, however, is felt by the poor and the vulnerable. Smit (2006:352) eloquently notes: "Among others, twenty years of protean funding policies have taken their toll on the private welfare sector", which mostly impacts on the poor, who are the service beneficiaries. This implies a serious questioning of the welfare sector's service delivery and contribution to achieving social development goals.

Although funds are of critical importance for service delivery, in itself they cannot determine the relationship between NGOs and government. Funding should be embedded in a well-established partnership built on mutual trust which provides an enabling environment for the spending of funds in an accountable manner. For this purpose, clear guidelines and criteria for the funding of social services are required.

An important ingredient of a NGO-government partnership in achieving social development goals should be empowerment of NGOs. Against a background of government doing lip-service to a partnership with NGOs and dictating expected services, NGOs should rather be supported as valuable partners in achieving social development goals.

It has never been doubted that government acknowledges the important role of faith-based organisations (FBOs), community-based organisations (CBOs) and non-profit organisations (NPOs) in social service delivery (Social Development Summit, 2006:3). It is the demarcation of that role in relation to the value and strengths that NGOs can bring to specific practice settings and regions which has not yet been fully recognised, determined and utilised in a joint partnership with government. Considering the diversity within the NGO sector in terms of operational fields and expertise, the knowledge base this sector can bring to a partnership could be a vital contribution to sustainable development. For government to empower NGOs a clear determination of the NGO sector's dimensions is needed in the respective regions. The size or volume of the NGO sector, its diversity, existing linkages, ability to influence policies and programmes, its relationship with private sector funders, financial independence and sustainability, member participation, infrastructure capacity, and access to information and innovativeness should be determined and measured as indicators for effective service delivery in order to identify the strengths and capacity that each NGO and the NGO sector as a whole can bring into the partnership. Weaknesses detected in any of these areas should become targets for intervention and improvement to ensure empowered partners in sustainable development goals.

Areas of collaboration and integration of services in order to strengthen partnerships in fighting poverty and marginalisation require that provincial governments and NGOs need to produce documentation on needs in specific areas with clear priorities for intervention, based on jointly constructed community profiles. Community profiling is a critical benchmark for the planning and provision of services and the scope and responsibilities of the NGO sector (Social Development Summit, 2006:16). Available expertise in both partner camps should then determine role designation.

Linkages at local, national and even international level can be an important measure of vitality in the local NGO community (USAID, 2007:11). Partnerships should be formed on vertical (grassroots, similar organisations) and horizontal (national and international) levels. Not only will the flow of information be stimulated, but a common base for dialogue with funders and government will be formed. 
Government should take a leadership role in guiding implementation of social welfare policies. The ISDM allocates government the role to "oversee" the implementation plan, which makes provision for the Model Implementation Advisory Team (MIAT) (Gauteng Welfare Summit, 2006:9). Within a sustainable partnership for social development partnership, this role "allocation" is challenged. The government, like the NGOs, is also a role player in implementation and hence both parties should have a role in "overseeing" implementation. It is thus proposed that the approach should rather be one of participation in implementation, as opposed to "overseeing" implementation. Joint monitoring and evaluation by both partners on pre-agreed measurable indicators would be a step forward in this regard.

A critical question in the NGO sector is: "How do we deal with the issue of the State demanding a high level of compliance to a range of requirements when in some cases it funds less than $50 \%$ of the costs of those services?" For an effective partnership it is critical that both partners determine the ratio between the funding and service in order to determine the area(s) of compliance to government. The percentage of government funds for a service should therefore be viewed as the percentage with which government can demand compliance from an NGO.

On various platforms, such as the Gauteng Welfare Summit (2006) and policy documents such as the ISDM, it is acknowledged that government and NGOs are mutually dependent on each other to ensure effective social service delivery and hence the achievement of social development goals in South Africa. In order to prevent a similar breakdown in the partnership between NGOs and government as was experienced in the recent past, it is critical to find an answer to the following question of the NGO sector: "How do we nurture a more structured and better sense of partnership between State and the NGO sector that moves us past blaming each other, promotes dialogue and collaboration, and builds the sector as a whole?" (Social Development Summit, 2006:21). This is possible if the solutions for the challenges embedded in the ISDM and the Policy on Financial Awards to Service Providers (Department of Social Development, 2005b) as outlined in this paper are sought jointly. Amongst these challenges, a key area is finalising clear guidelines on the funding of NGOs.

\section{Guidelines for the funding of NGOs}

Government responds to its obligation of poverty alleviation in three ways: social security, subsidisation of the services by NGOs, and direct services by civil servants in a number of departments. Since 1994 the new democratic government has vigorously reached out to the poor through providing increased access to social grants. Social grants, subjected to means tests, succeed in alleviating the situation amongst the poorest of the poor who previously had no income at all. Limitations in reaching the poorest of the poor who qualify for social grants are currently being addressed by the government's initiative to reach out to the remote rural areas through mobile trucks and the use of modern technology to process applications. The outcome of such applications is available in one day (Department Social Development, 2007:1). But, as already indicated, whilst government expanded its safety-net by allocating the lion share of its social welfare budget to social security, it had less than $10 \%$ to fund its own and NGO social welfare services. The neglect of social services has had a serious impact on delivering on the social development agenda which is compounded by the fact that the number of South Africans depending on social grants is a growing concern, especially as no exit levels were planned over the last 13 years of democracy (Department of Social Development, 2006b).

A first step in addressing this situation was the shift of the function of social security to the South African Social Security Agency (SASSA). NGOs in Gauteng now share a significant portion of 
the total budget of the Department from the 2006/07 to 2008/09 financial years (Social Development Summit, 2006:3). During this period the subsidies in Gauteng province increased from $43 \%$ to $48 \%$ as a portion of the total budget of the Department over the Medium Term Expenditure Framework (MTEF) (Social Development Summit, 2006:4). Of theses subsidies, services to children, women and families receive the largest portion, i.e. $48 \%$, followed by $24 \%$ allocated to services to older persons and $16 \%$ to persons with disabilities (Social Development Summit, 2006:3). The Gauteng province is also to be saluted as one of the provinces that subsidised NGO social workers' salary increments on a basis of 75 to $77 \%$ of the salary levels of social workers in the Department. Although the discrepancy between government and NGO salaries remains high and a contentious issue, the commitment of government to bridge the gaps needs to be acknowledged. The spirit of the commitment is important in finding solutions for the challenges imposed by the limitations of the financing policies for developmental social welfare in the province and, since financing of social welfare is a national issue, for the whole of South Africa.

The funding of developmental social welfare services by NGOs is based on policy and procedure documents; however, these documents are in different stages of development (Social Development Summit, 2006:12). The result is that there is no coherent financing policy available for social service delivery to address the issue of financing significantly (Social Development Summit, 2006:12). This includes no structured and accessible way in which the NGO sector can engage in budget planning processes for the whole sector (Social Development Summit, 2006:12).

Smit (2006:351) summarises the history of financing of social welfare services in South Africa and captures the financing trends and challenges since the adoption of the White Paper for Social Welfare in 1997:

- The first policy, entitled Policy for Financing of Developmental Social Services, was issued by the national Department of Welfare in draft form only in May, 1998 and identified four main categories of service: empowerment; community intervention; residential intervention and resource development; and planning and management (Policy for Financing of Developmental Social Services, 1998 in Smit, 2006:351). It was not known why this policy was not adopted or what the cost of its development was (Smit, 2006:351).

- The second policy, the Financial Policy for Developmental Social Services, was implemented on 1 April 1999 and identified four categories of service: prevention, early intervention, statutory process, and a continuum of care and developmental services (Financial Policy for Developmental Social Services, 1998 in Smit, 2006:351). This policy focused mainly on families, communities, children, youths, women and older persons. While adopted, it was never fully implemented and thus necessitated the continuation of the social work-based subsidy scheme, where organisations' subsidy would continue to be determine by the old rather than the new policy, i.e. looking at head counts of clients for determining social work salaries (Smit, 2006:351). This policy also did not survive. It was very hastily prepared without consultation with the Portfolio Committee on Welfare and Population Development was not consulted before the adoption of the policy and is seen as a political document which was "an optimistic and ambitious policy" to implement (Portfolio Monitoring Group, in Smit, 2006:351).

- The newest policy, the Policy on Financial Awards to Service Providers, was approved in February 2004 for implementation on 1 April 2005 and looks more broadly at the funding of services, "whereas the previous strategy looks only at social workers salaries ... It has the 
objectives of transformation of NGO service delivery as well as the way they are funded. The policy seeks to promote accountability and good governance" (Policy on Financial Awards to Service Providers, 2005 in Smit, 2006:353). This policy introduces new concepts such as transformation and performance criteria that beneficiary organisations have to meet (Smit, 2006:353). Although a procedural manual has appeared in support of successful implementation, the policy still remains vague (Smit, 2006:353).

Although the Policy on Financial Awards to Service Providers (2005) brought with it a significant shift in welfare policy in order to accommodate the developmental approach to social welfare, there are still major challenges ahead in order to "develop a uniform framework for the financing of social service programmes" (Department of Social Development, 2006a:42) that could deliver on the achievement of social development goals.

The strength of the Policy on Financial Awards to Service Providers (2005) is geared towards ensuring achievement of priorities in terms of transformation and developmental services to designated groups, i.e. children, youths, the aged, people with disabilities, women, victims of violence and those affected by substance abuse and HIV/AIDS (Department of Social Development, 2006a). Service providers have generally aligned themselves to these priorities as well as the principles underpinning the objectives of the said policy, given the demographic profile of the country with a basically youthful population of 46 million, of which 23 million are female, $79 \%$ are black and South Africa being one of the countries with the highest occurrence of HIV/AIDS, especially in the reproductive age cohort (Statistics South Africa, 2006). More than one third of the population of 46 million is unemployed, with almost one third living below the poverty line - in both cases black South Africans (Statistics South Africa, 2006). Various attempts by government to address the situation such as the Expanded Public Works Programme and the Skills Development Act (No. 97 of 1998) are commendable. Unfortunately the process of achieving results is deterred by a slow pace of implementation and evaluation. The vague implementation and evaluation guidelines of the Policy on Financial Awards to Service Providers (Department Social Development, 2005b) do not assist the social welfare sector in fast tracking the desired development in South Africa. This vagueness is embedded in the following limitations and challenges.

Whilst wanting to fund services in the NGO sector, government prescribes definite conditions. The aim of the Policy on Financial Awards to Service Providers (Department Social Development, 2005b:3) in financing service providers in the social development sector is (1) to facilitate transformation, (2) redirect services and resources and to (3) to ensure effective services to the poor and vulnerable, "to ensure a better life for themselves in partnership with them and with those who are committed to building a caring society".

Requirements for such funding are based on NGOs' business plans, budgets, governance structures, constitutions, registration, volunteers and service consumers. At the same time indicators to evaluate effective and efficient service delivery are not stipulated in the Policy on Financial Awards to Service Providers (Department Social Development, 2005b:26-28). This gap is demonstrated in government's audits of NGOs services. Whilst the purpose of such evaluation should be benchmarked against delivery on the above stipulated aim, the practice reality reveals that the indicators for these audits actually reflect a residual welfare model as opposed to a developmental model. This conclusion is based on the observation of emphasis by one NGO in the field of disability. The annual audit done by the Department of Social Development appears to focus primarily on casework. Evaluation reports elaborate on the file administration of individuals, casework planning and report writing with limited feedback on any community 
projects. Application for funding is made in the form of service plans (a prescribed business plan guideline), which is expected by the end of September of each year. Conditions to succeed in accessing funding are focused on healthy financial principles within the organisation (Department of Social Development, 2005b).

If an application for funding is approved, a contract is signed for quarterly payments. Currently, the mentioned NGO receives a subsidy amount of R11,194 per month for a social worker and a social auxiliary worker. Only R3,667 of this amount is allowed for administrative costs (transport, pension, communication, stationary, support staff remuneration, insurance, maintenance and other costs). Processing the documents that must be submitted by an NGO, however, is not simple and is extremely cumbersome with multiple re-signing of documents and first payments often not being received before August, four months after the start of the financial year. NGOs concur that management and delivery of services are often undermined by the delays and administrative problems surrounding subsidy payments (Social Development Summit, 2006:12).

Clearly, bureaucratic processes can seriously impact on social service delivery and thus the achievement of social development goals. The reasons for the slow implementation should, however, also be determined on a competency level, both within government and the NGO sector. With regard to finances, Smit's (2006:358) conclusion in his study on funding strategies is stated bluntly as: "this [social welfare] sector faces major financial difficulties partly as a result of poorly conceived and executed policies" (Smit, 2006:358), but the author continues: "[t]he private welfare sector is not without blemish either. Its inability to better secure itself ... cannot be blamed on government". This security includes, amongst other things, knowledge and skills in the writing of business plans to access funds, in budgeting processes and where and how to access funds.

From a small sample organisations in Gauteng, it appeared that government subsidises 38\% of their income, followed by $36 \%$ from various sources such as investment, fees, rental, interest income, followed by $20 \%$ from local and international donors (Social Development Summit, 2006:8). What these organisations indicated is that they all have the potential to raise funds and that the additional funds contribute positively to their financial sustainability, which is perceived by government as these organizations having built a strong resource base over time (Social Development Summit, 2006:9).

While it is true that NGOs should accept their autonomy and responsibility to seek independent funding from government, this may be more viable for middle-class urban organisations. CBOs find it almost impossible to obtain such funds at any given time. This raises a critical issue of whose responsibility it is to capacitate new and emerging NGOs. To deliver on the transformation agenda, the Department has to reprioritise its financial resources in favour of the historically disadvantaged communities and organisations (Social Development Summit, 2006:6). If there are areas without services, either government must provide these services or seek the help of, and provide support for, NGOs and CBOs to fill the gaps. The NGO sector argues that the solution is not to move funds away from those receiving subsidies only just managing to cope (Social Development Summit, 2006:14). The premise for this argument is that it cannot be done at the expense of the existing organisations and nor at the expense of client systems. Resources therefore cannot be taken from the existing organisations to capacitate emerging NGOs. Although the Department has funded the cost of mentoring by established organisations in the form of providing a service fee (Social Development Summit, 2006:9), mentoring cannot be established only in monetary value. The Tsepong Day Care Centre in Refilwe is a point in case. This CBO 
accommodates 73 children with disabilities in a newly constructed building. Neither manager nor caregivers possessed any skills to perform accountable services other than to watch over the children whilst in their care. An established NGO in the field of disabilities observed this and befriended the Centre. As a result, the NGO included the manager of the Centre in its computer and financial management training programme, included kitchen staff in an induction programme on domestic hygiene, catering and compiling of menus, trained two caregivers in physical care and stimulation games, and involved a volunteer occupational therapist for the Centre on a weekly basis. The value of this initiative could never be measured in monetary terms. But it created an opportunity for an established NGO to contribute to transformation and at the same time establish a long-term partnership. It importantly helped build a stronger social welfare sector for achieving social development goals as emerging organisations are community-based and close to the poor and marginalised in society. NGOs should not necessarily demand up front funding for an opportunity such as that of the Tsepong Day Care Centre, but rather advocate that capacitybuilding should be recognised and evaluated as an indicator of resource allocation for social service delivery within their own organisation.

Given the above funding challenges, it is possible for NGOs to manage the challenges of implementing the Policy on Financial Awards to Service Providers (Department of Social Development, 2005b) through partnering with government departments by (1) identifying social development goals and objectives for specific work areas; (2) constructing specific tasks and services to achieve objectives with aligned standards and time frames; (3) determining reasonable quantities of output per time frame; (4) realistic costing of each task and service in order to compile a feasible budget; (5) evaluating NGOs individually to assess their means of fund-raising to sustain their budgets realistically; (6) negotiating a percentage of subsidisation per NGO; (7) making payments within pre-agreed time frames; (8) undertaking social welfare service audits according to specified task outcomes per organisation; and (9) providing structured feedback with guidelines to rectify shortcomings. Such forms of collaboration will, however, require an established partnership between NGOs and the Department of Social Development as discussed earlier. But an established partnership needs to be sustained. A key factor in sustaining an established partnership is attached to the liaison person between an NGO and government. Government should allocate one coordinator to an organisation who can fully engage in all the aspects of the organisation with regard to service delivery, i.e. the planning, implementation, monitoring and evaluation stages. This involvement should also include regular sight visits so that the nature and scope of the services provided by the organisation are fully understood from practice experience and not merely as a paper exercise.

It is also anticipated that funding for longer time frames rather than annually would serve the NGO sector more appropriately. Disadvantaged communities present their own pace towards new developmental interventions and negotiated participation in projects. Limited resources in any poor community means time is required to establish basic facilities and engage community members. A three-year funding contract need not prevent annual evaluations to review and determine progress.

It is further anticipated that structuring state subsidisation in the afore-mentioned form will also stimulate the formation of interlinkages between NGO and CBO networks. If organisations are to play a significant role in sustainable development of the country, they should then have strengths in a number of key sectors such as education, health, labour and enterprise development (USAID, 2007:11). 
Lessons from the first decade of freedom indicate that all policies need to be costed for, among other things, capacity and infrastructure to enable government to integrate the costs into the Medium Term Expenditure Framework (MTEF), thereby managing public expectations and ensuring that resources are appropriately allocated (Gauteng Provincial Government, 2005:19). In addition, to impact on social development, social services should be financed and thus resources allocated within a programme framework which has been mooted for many years but with no real or tangible developments in this direction being evident as yet (Social Development Summit, 2006:16). The first step in this direction is to implement funding based on minimum standards and the cost of services and then to develop programme financing as additional financing (Social Development Summit, 2006:16).

One of the most important areas in which the ISDM takes social services forward is its commitment to the incorporation of norms and standards into the work of the sector (Gauteng Welfare Summit, 2006:15). As indicated earlier, work is in progress to determine standards for the costing of general social services. The amounts should be based on an actual costing of services and take into account the principle of sustainability, the need for the service and the target groups as well as the minimum standards for the particular service (Social Development Summit, 2006:16).

To meet the above challenges, the responsibilities of the government and the NGO sector need to be clearly conceptualised and articulated in the policy and founded on the principles of a sound partnership as indicated above (Social Development Summit, 2006:14).

\section{Indicators for monitoring and evaluation}

Monitoring and evaluation on the delivery on the ISDM should be based on measurable indicators as has already been indicated in this discussion. To determine whether the social welfare sector really delivers on its social development goals, specific indicators for developmental social service outcomes should be identified. In this paper reference is made to some indicators which will fast-track the implementation of the ISDM as a mechanism to achieve social development outcomes, i.e. transformation, participation and quality assurance.

Transformation: In achieving social development goals a key indicator in the social welfare sector was transformation from a colonial, apartheid to a democratic, developmental social welfare system. According to the NGO sector, the statement is made that "realignment of services in line with government policy has not been the general trend" without any evidence being supplied and hence is regarded as an unfair statement (Social Development Summit, 2006:13). While the transformation to shift service delivery to the black poor and the vulnerable has been an easier goal to achieve, it is on the management and personnel level where organisations are more challenged. An organisation should have a measurable scorecard for transformation in terms of representation from designated groups (black people, women, persons with disability). It is understandable that immediate changes are impractical and create resentment, but an approach by government of gradual growth in numbers to obtain the ultimate presentation would be appreciated. One NGO in the field of disability, for example, commenced in 1993 with the inclusion of two persons with disabilities, followed by the inclusion of representation from poor communities over the next four years. In 1999 the founding document was adjusted to prescribe the election and appointment of $60 \%$ black people, $50 \%$ persons with disabilities, $50 \%$ females and at least two service consumers on the governance board. By 2004 the organisation's management, staff and client base were fully transformed. Even though this process took ten years, the underlying principle is to build the transformation on a well thought-through plan 
which must be agreed upon by both government and the NGO. Each NGO has its own history, characteristics, responsibilities and commitments which should be recognised (Social Development Summit, 2006:19) when criteria for transformation are determined. The intention is not to use an NGO's unique nature as an excuse for not transforming; NGOs must be approached individually to determine what their transformation agenda should look like, given its field of service and other indicators such as volunteer-management.

Participation: It is observed in practice, both in government and in the NGO sector, that many social workers, in particular those at grassroots level, are not informed about policies such as the ISDM and the Policy on Financial Awards to Service Providers, or even have an in-depth understanding of the White Paper for Social Welfare. This inevitably contributes to the slow implementation process. Participation is needed not only at summit levels. Local government and NGOs in their region should be partners, where both parties contribute, evaluate, internalise and implement the goals that ought to be achieved. Presently, local forums play a significant role in bringing all parties together. It is experienced that the end results of these forum meetings, however, tend to be insignificant, with "partners" having different agendas. Instead of designating one government official to an NGO with the view to establish an ongoing partnership where all parties commit to delivery, all the government planning officials in the province are involved with all NGOs, which consumes valuable time and leaves NGOs distraught at the additional administration due to duplication and often contradictory expectations. Often when the "partners" meet, arguments regarding policies erupt instead of their focusing on problems and obstacles and seeking common solutions to resolve them.

Quality assurance: Indicators should be developed across the spectrum of service delivery, including the following:

- Physical indicators per area: Demographics of population; distance from main office; local intake points;

- Human resource indicators: Professional and administration personnel; project workers; volunteers;

- Community development projects: Research project(s); project operations and achievements, such as numbers linked to income-generation projects; committee functions; campaigns and affects, community involvement;

- Group interventions: Number; participants, participation; objectives for meeting needs;

- Individual interventions: Intakes; intervention sessions; referrals; financial aid; therapies and outcomes; case closures and reasons;

- Statutory interventions: Numbers; types; court appearances and orders; supervision and reconstruction services;

- Administration: Files; recording; reports; minutes; data base processing; claims; forms;

- Management (supervision): Planning; sessions; reports/notes; induction, capacity building, evaluation, consumer involvement and feedback, policy development;;

- Costing and funding: Budgets, proposals, innovative savings, substitution of costs in case of worker absence.

\section{Legislative framework for the social welfare sector}

There is no holistic legislative framework in place to formalise the mandate of social welfare in South Africa. Legislation in the sector is fragmented in terms of specialised social service areas 
such as the aged, child care, probation, drug dependency, mental health, domestic violence, among others (see the Department of Social Development (2006a) for a comprehensive account). The White Paper for Social Welfare (1997) therefore needs to be urgently transformed into a legislative framework that makes provision for defining developmental social welfare, the roles of government departments and NGOs with regard to social welfare services and their financing (Social Development Summit, 2006:20).

\section{CONCLUSION}

The social welfare sector is a key role player in determining whether South Africa is to either remain in a welfare state or to advance to a fully fledged developmental state. It is the social welfare sector that engages with government's policies in fighting poverty which the First Lady, Zanele Mbeki, has criticized in saying that more welfare will not buy the poor out of their misery (Boyle, 2005:1). Social service professionals should not be party to the "we" that the First Lady refers to in the following statement: "We should not make a welfare state and call it a developmental state" (Boyle, 2005:1). In line with this paper's argument that social welfare can be "developmental", the "welfare" challenge referred to by the First Lady is interpreted as providing social grants with clear exit levels that is supplemented by developmental social services to deliver on a well articulated social development agenda.

This shift is possible because the social welfare sector is committed to reducing poverty and inequality in South Africa. Although the sector has made progress in promoting social justice for all through social grants, the challenge remains with regard to addressing the backlog on its social development goals by implementing social development intervention strategies in developmental social service delivery.

A refined Integrated Service Delivery Model (ISDM) according to the challenges outlined in this paper provides the mechanism to redefine the social welfare sector's social development agenda, create an enabling environment for developmental social service delivery, facilitate its implementation, and provide the monitoring and evaluation indicators to enable the sector to account for achieving its social development goals. Enabling policies such as the Policy on Financial Awards to Services Providers (2005) should be aligned to achieve the goals of the IDSM. To fast-track this process, the social welfare sector should prioritise the development of a legislative framework for social welfare. Our conviction that the social welfare sector "can and should, through intersectoral planning and budgeting, play a much stronger role in building the development state ... [and that] a strong developmental social welfare system is a prerequisite for successful development" (Gauteng Welfare Summit, 2006:11-12) provides the fuel and inspiration for social welfare policies to impact on social development.

\section{REFERENCES}

BOYLE, B. 2005. First Lady: State has failed the poor. Sunday Times, 11 December 2005:1.

DE JAGER, M.S. 2005. Social workers' experiences relating to the implementation of a developmental approach in Port Elizabeth. Proceedings of the ASASWEI Conference 2005 on Democracy, Development, Delivery Mapping the future contribution of the social service professions. Hosted by Department of Social Work, University of Stellenbosch, 6-7 September 2005.

DEPARTMENT OF SOCIAL DEVELOPMENT. 2005a. Policy on Financial Awards to Service Providers. 
DEPARTMENT OF SOCIAL DEVELOPMENT. 2005b. Procedure guidelines for the implementation of the Policy on Financial Awards to Service Providers.

DEPARTMENT OF SOCIAL DEVELOPMENT. 2005c. Media Statement: Social Development Launches New Approach to Service Delivery. 23 November.

DEPARTMENT OF SOCIAL DEVELOPMENT. 2006a. Integrated Service Delivery Model towards improved social services.

DEPARTMENT OF SOCIAL DEVELOPMENT. 2006b. Discussion Document. Linking social grants beneficiaries to poverty alleviation and economic activity. 1 November.

DEPARTMENT OF SOCIAL DEVELOPMENT. 2007. Media Statement: Launch of SASSA Outreach Programme and One Stop Centre in Greytown. 18 June.

GAUTENG PROVINCIAL GOVERNMENT. 2005. Social Development Strategy for the Gauteng Province (GSDS). Building a province wherein the people are healthy, skilled and productive, the government is caring and responsive to the needs of its citizenship and democracy are deepened. 7 September 2005.

GAUTENG WELFARE SUMMIT, 2006. The Integrated Service Delivery Model: A Review of the Gauteng Department of Social Development's response, and an NPO perspective. Prepared by: Frans Rammutla and Nono Yende, Gauteng Department of Social Development and Beena Chiba, Maya Keel and Jackie Loffell, Gauteng Welfare, Social Service and Development Forum. 26-27 October.

GRAY, M. \& CROFTS, P. 2004. Partnerships: Marrying the strengths and resources of diverse interest groups, Social Work/Maatskaplike Werk, 40(3):246-259.

GRAY, M. 2006. The progress of social development in South Africa. International Journal of Social Welfare, 15(Supplement 1):S53-S64.

GREEN, S. \& NIEMAN, A. 2003. Social development: Good practice guidelines. Social Work/Maatskaplike Werk, 39(2):161-181.

IFE, J. 1995. Community development. Creating community alternatives - vision, analysis and practice. Australia: Addison Wesley Longman.

LOMBARD, A. \& DU PREEZ, J. 2004. Challenges for building partnerships in social development. Social Work/Maatskaplike Werk, 40(3):232-245.

LOMBARD, A. \& KLEIJN, W.C. 2006. Statutory social services: An integrated part of developmental social welfare service delivery. Social Work/Maatskaplike Werk, 42(3/4):213233.

LOMBARD, A. 1996. Developmental social welfare in South Africa: A theoretical framework. Social Work/Maatskaplike Werk, 32(2):162-172.

LOMBARD, A. 2005. Impact of social services on human, social and economic development and the promotion of human rights in South Africa. Social Work/Maatskaplike Werk, 41(3):209228.

LOMBARD, A., WEYERS, M.L. \& SCHOEMAN, J.H. 1991. Community work and community development. Perspectives on social development. HAUM-Tertiary.

MIDGLEY, J. 1995. Social development. The developmental perspective in social welfare. London: SAGE Publications. 
PATEL, L. 2005. Social welfare and social development. Oxford Southern Africa.

REPUBLIC OF SOUTH AFRICA (RSA). 1997. Ministry for Welfare and Population Development. White Paper for Social Welfare. Government Gazette, Vol. 386. No. 18166 (8 August). Pretoria: Government Printer.

REPUBLIC OF SOUTH AFRICA (RSA). 1998. Ministry of Labour. Skills Development Act (Act No. 97 of 1998). Government Gazette, Vol. 401, No. 19420 (November 20). Pretoria: Government Printer.

REPUBLIC OF SOUTH AFRICA (RSA). 1999. Ministry for Welfare and Population Development. Financing Policy for Developmental Social Welfare Services. Government Gazette No. 19888. Pretoria: Government Printer.

REPUBLIC OF SOUTH AFRICA (RSA). 2004. Budget Speech. Minister of Finance, Trevor A Manuel, 18 February 2004.

REPUBLIC OF SOUTH AFRICA (RSA). 2005. Budget Speech. Minister of Finance, Trevor A Manuel, MP., 23 February 2005.

REPUBLIC OF SOUTH AFRICA (RSA). 2006. State of the Nation Address of the President of South Africa, Thabo Mbeki: Joint Sitting of Parliament, 3 February 2006.

REPUBLIC OF SOUTH AFRICA (RSA). 2007a. Budget Speech. Minister of Finance, Trevor A Manuel, MP, 21 February 2007.

REPUBLIC OF SOUTH AFRICA (RSA). 2007b. Budget Speech. Minister of Social Development, Zola Skweyiya, 28 March 2007.

SCHOEMAN, M. 2001. South Africa's political economy in a global context. In: VENTER, A. (ed) Government and politics in the new South Africa. An introductory reader to its institutions, processes and policies ( $2^{\text {nd }}$ ed). Pretoria: Van Schaik.

SMIT, A. 2006. Funding strategies: Surviving imperial intentions, protean policies and ruthless reality. Social Work/Maatskaplike Werk, 41(4):485-360.

SOCIAL DEVELOPMENT SUMMIT. 2006. Financing and capacity building of non-profit organizations. Strengthening partnership to fight poverty and marginalisation. Compiled by Themba Msimanga Department of Social Development, Mike Batley - NPO (Restorative Justice Centre). 26-27 October.

STATISTICS SOUTH AFRICA. 2006. Stats in Brief.

STURGEON, S. 1998. The future of casework in South Africa. In: GRAY, M. (ed) Developmental social work in South Africa: Theory and practice. Claremont: David Philip Publishers (Pty) Ltd.

USAID. 2007. New Partnership Initiative: NGO Empowerment.

Prof Antoinette Lombard, Department of Social Work and Criminology, University of Pretoria, Pretoria, South Africa. 